\title{
Why Are Wealthier Countries More Vaccine Skeptical?: How Internet Access Drives Global Vaccine Skepticism
}

\author{
Kristin Lunz Trujillo ${ }^{1,2}$ and Matthew Motta ${ }^{3}$ \\ ${ }^{1}$ Corresponding Author; Dept. of Political Science, University of Minnesota - Twin Cities \\ 2Dept. of Political Science, Carleton College, email: lunzx007@umn.edu \\ ${ }^{3}$ Dept. of Political Science, Oklahoma State University, email: matthew.motta@okstate.edu
}

\begin{abstract}
Vaccine skepticism interferes with governments' abilities to maintain public safety and fight costly and deadly diseases. Contrary to expectations, vaccine skepticism positively predicts country wealth, rather than negatively. We propose that higher access to the internet facilitates the spread of anti- vaccine misinformation throughout society, though particularly for those lower in scientific and medical expert trust, which we call the Online Accessibility hypothesis. Alternatively, it could also be that the relationship between country wealth and vaccine skepticism is being driven by citizens in richer countries who fail to consider the risks of vaccine-preventable diseases because they are rarely experienced directly, which we deem the Out of Sight hypothesis. To test our expectations, we merge country-level data with nationally representative survey data $(\mathrm{N}=149,014)$ from 144 countries. We find evidence for the Misinformation Accessibility hypothesis; people in countries with greater internet access are significantly more likely to be vaccine skeptical. Further, we examine Americans' vaccine attitudes before and during the COVID-19 outbreak - a time and place where a communicable disease is very much 'in-sight' - as a supplemental test of the Out of Sight hypothesis, and find anti-vaccine attitudes are similar to, or even higher than, pre-outbreak levels.
\end{abstract}

Keywords: misinformation, vaccine attitudes, public opinion, cross-national, vaccine skepticism, political communication, health policy 
Vaccine skepticism is a global phenomenon that threatens public health and safety. Vaccine skeptics are more likely to pursue alternative vaccination schedules and to skip vaccination altogether, making it possible for nearlyeradicated diseases to return and spread (Joslyn and Sylvester 2017; WHO 2019). Similarly, those who hold negative beliefs toward vaccines are more opposed to pro-vaccination policies (Stecula et al. 2020). Vaccine skepticism also poses significant political challenges. For example, members of the public holding anti-vaccine attitudes are not only more likely to oppose pro-vaccine policies; they have also helped block state-level legislation for mandatory vaccination or stricter vaccination policies in the U.S. and elsewhere (Joslyn and Sylvester 2017; Motta et al. 2018).

The potentially harmful consequences of vaccine skepticism are particularly prominent in light of the 2020 COVID-19 outbreak. Countries around the world have implemented policies to mitigate the virus's negative health and economic consequences, which will likely stay in place until a vaccine becomes available. However, vaccine skepticism threatens to undermine this plan, potentially leading to disastrous long-term effects.

Additionally, vaccine skepticism has been harnessed by politicians to gain electoral support. Populists in Italy, the U.S., and elsewhere have pushed for nonmandatory vaccination policies (Bosley 2018; Buncombe 2018). Western Europeans who believe that vaccination is not important are significantly more likely to vote for populist parties, likely because both populism and vaccine skepticism are linked with anti-intellectualism and a distrust in experts and elites (Kennedy 2019; Merkley 2019). Vaccine skepticism and its relationship with policy and politics is part of a broader contemporary trend toward embracing 
anti-science attitudes, including those inconsistent with consensus about climate change, GM food, and several other topics.

These examples underscore a point raised in previous public opinion research - people in wealthier countries tend to hold more skeptical attitudes toward vaccine safety, efficacy, and importance (Larson et al. 2016; Gallup 2019). This trend is somewhat unexpected; as countries develop, citizens become better educated, and have better access to health information and health care, so holding attitudes in line with medical consensus should be more common than in countries that are poorer and that have less resources. Therefore, why this relationship between country wealth and vaccine skepticism exists remains an open question.

We expect that higher levels of vaccine skepticism in wealthier countries are being driven by what we call the Online Accessibility hypothesis; vaccine skepticism is higher in wealthier countries because their citizens have greater access to modern forms of media, particularly the internet, which enables the spread of anti-vaccine misinformation (Kata 2010). If this hypothesis is correct, internet connectivity should be positively correlated with vaccine skepticism.

This hypothesis is tested against an alternative explanation, the Out of Sight hypothesis. Under this hypothesis, people in more developed countries are more skeptical of vaccines because they, due to medical advancement, have grown unfamiliar with the significance and importance of fighting infectious diseases. Such an expectation has been predicted by game theoretic models; as vaccination rates increase, herd immunity kicks in and free ridership becomes an issue (Bauch and Earn 2004). If this scenario is correct, then preventable disease cases per capita should be negatively correlated with vaccine skepticism, thus accounting for the 
link between country wealth and vaccine skepticism.

Using nationally representative data from 144 countries, we test these hypotheses. Our analysis finds support for the Online Accessibility hypothesis and little support for the alternative Out of Sight hypothesis. We find that countrylevel internet connectivity is associated with individual-level vaccine skepticism, controlling for other factors. Surprisingly, we find that the number of communicable disease cases percapita is positively correlated with vaccine skepticism, which is the opposite of what we would expect under the Out of Sight hypothesis. Critically, we find that internet connectivity (but not disease prevalence) explains away any effect of country-level wealth on vaccine attitudes. Consistent with previous work on the microfoundations of misinformation endorsement (e.g., Flynn et al. 2018; Miller et al. 2017; Motta 2018), we also note that the effect of country internet connectivity on vaccine attitudes tends to be stronger for the types of people most likely to consume online misinformation about vaccines (i.e., those with low trust in relevant experts and the government). Further, in a supplemental test of the Out of Sight hypothesis, we find that Americans' vaccine attitudes and levels of misinformation endorsement remain consistent before and during the early stages of the COVID19 pandemic - a period of high disease salience and awareness of personal risk.

\section{The Origins of Vaccine Skepticism}

Vaccine skepticism refers to suspicions about vaccine safety, effectiveness, and importance (Larson et al. 2016). Vaccine skeptics are much more likely to forego childhood vaccination, compared to those who are vaccine confident (Joslyn and Sylvester 2017). People higher in vaccine skepticism are also more likely to score higher in certain psychological traits, such as conspiratorial 
thinking, disgust sensitivity, moral purity, sensitivity to blood and needles, and reactance, among others (Callaghan et al. 2019; Carpiano and Fitz 2017; Clifford and Wendell 2016; Hornsey et al. 2018; Jolley and Douglas 2014; Joslyn and Sylvester 2018; Lunz Trujillo et al. 2020). Furthermore, those who are vaccine skeptical tend to mistrust experts, including scientists, medical professionals, the pharmaceutical industry, and other related groups, such as academics (Kata 2012; Motta et al. 2018; Prior 2003).

Although less than $10 \%$ of people around the world are vaccine skeptical (Gallup 2019), there is nevertheless significant variation in vaccine skepticism by country. In some cases, vaccine skepticism is high enough to lower vaccination rates and compromise herd immunity. Generally, vaccination rates are positively correlated with country wealth (Restrepo-Méndez et al. 2016); this is likely due to differences in access to and knowledge about vaccines and medical care (Aslam and Kingdon 2012; Rammohan et al. 2012). However, people in wealthier countries simultaneously tend to express higher levels of vaccine skepticism than people in less wealthy countries (Larson et al. 2016; Gallup 2019). This is surprising, given that people living in wealthier countries not only have easier access to vaccines and greater awareness of their benefits, but also tend have higher education levels. Greater parental education levels generally lead to better child health outcomes via greater knowledge of science and health information, as well as better health-related decision-making skills (Aslam and Kingdon 2012; Rammohan et al. 2012). However, studies examining the relationship between education level and vaccine skepticism at the country and individual levels have produced mixed results in more developed countries (see Larson et al. 2014 for a review).

We also note that several other country-level contextual factors (aside from wealth) might impact public vaccine skepticism, including scandals and negative 
associations with medical systems (Gallup 2019; Larson et al. 2016;

Rabesandratana 2019). Therefore, countries may vary in vaccine skepticism levels due to idiosyncratic factors. As we discuss in detail below, our study of the potential causes of the "wealth effect" described above ought to account for these contextual factors.

Overall, this line of research documents a disconnect between country-level wealth (which we might expect to improve positively toward vaccines) and vaccine skepticism. In what follows, we substantiate - and, later, put to the empirical test - two competing theoretical explanations for this puzzling pattern of effects. If either explanation is truly responsible for the relationship between wealth and skepticism, we expect that the corresponding factor should fully account for the relationship between wealth and vaccine skepticism.

\section{Online Accessibility Hypothesis}

One possible reason why we see less vaccine confidence in wealthier countries is due to the online creation and spread of misinformation. Access to mass telecommunications, particularly the internet, is higher among wealthier countries, though emerging or developing countries have also experienced increased internet access in the past decade especially (Poushter 2016). The internet has the ability to greatly increase people's exposure to information, including their exposure to misinformation and disinformation. This has been well documented in the case of vaccine misinformation; anti-vaccine websites and social media posts on the internet are widespread (Bean 2011; Betsch and Sachse 2012; Kata 2010; 2012). Much of this has to do with a lack of gate-keeping in online information environments (Ennals et al. 2010). Furthermore, certain online communities such as 
alternative medicine blogs, message boards, and social media networks provide a forum to reinforce misinformation acceptance via a community of like-minded individuals (Bode and Vraga 2015; Tavris and Aronson 2008). In addition, people frequently and actively use the internet to seek out health information in particular, which has had the effect of increasing lay peoples' perceptions of their own medical and scientific expertise at the expense and mistrust of experts (Motta et al. 2018; Prior 2003). Further, misinformation is much easier to create and disseminate with access to the internet (Kata 2010), thus creating both a spike in misinformation creation and consumption within a particular country.

In addition, individual online access is not the only way to get information and misinformation originating from online sources. People can also indirectly receive online misinformation from "opinion leaders" in one's social networks, such as family, friends, and co-workers. This is a well-known phenomenon, called a two-step information flow; those with media access can explain and spread the information to others (Katz and Lazarsfeld 1955). More recent scholarship has found evidence of two-step and multi-step flows of information online and from social media (Choi 2015; Hilbert et al. 2017). Therefore, when thinking about cross-national differences in Online Accessibility, it is important to consider the misinformation access as an entire society rather than for each individual within the society.

For these reasons, we pose the Online Accessibility hypothesis as follows:

Main Hypothesis (Hypothesis 1a): Vaccineskepticism should bepositively correlated with internet accessibility, due to the internet fostering increased creation, dissemination, and consumption of misinformation. 
Not all individuals are equally likely to seek out and accept misinformation, however. People who distrust the government and/or scientific and medical experts are more likely to endorse misinformation and conspiracy theories about vaccines, politics, and public health (Klofstad et al. 2019; Miller et al. 2016; Motta 2018; Stecula et al. 2020). Similarly, individual-level confidence in vaccines depends in part on trust in the competency and reliability of health services, the pharmaceutical industry, and the perceived motivations of politicians (Jolley and Douglas 2014; Larson et al. 2011; 2014; MacDonald and the SAGE Working Group 2015, 2). Vaccine skepticism's relationship with distrust in experts and the government also occurs because some vaccine misinformation points to powerful entities purportedly covering up the harmful nature of vaccines to increase profits at the expense of public health.

Furthermore, people who are already skeptical or hesitant of vaccines should also be more likely to adopt misinformation that comports with their prior feelings toward modern medicine (Kraft et al. 2015; Kunda 1990; Taber and Lodge 2006). Therefore, even if mistrustful people come across the correct information about vaccines - which may occur with greater access to the internet or social media they are psychologically motivated to reject this new information if it aligns with medical consensus. That said, however, some scholars have noted that the internet may provide an opportunity for misinformation or conspiracy theories to be corrected (Bode and Vraga 2015; Clarke 2007; Messing and Westwood 2014). In sum, if the Online Accessibility hypothesis is correct, increased internet availability and access should facilitate the transmission of vaccine misinformation (which in turn promotes vaccine skepticism), especially for individuals who are mistrustful of relevant experts and governmental entities. Therefore: 
Hypothesis 1b: The positive relationship between internet connectivity and vaccine skepticism is stronger for respondents low in trust of medical and governmental experts, compared to those who are more trusting of these experts.

\section{Out of Sight Hypothesis}

Alternatively, people in wealthier countries may be less likely to engage in protective behaviors due to free riding; people will not vaccinate if they do not perceive disease prevalence as a threat (Schwarzer and Fuchs 1996).

Literature on vaccination rates from behavioral economics posits that when the majority of a population becomes vaccinated, individuals are more likely to conform to the majority norm (Hershey et al. 1994). Conversely, as populations become more vaccinated, there is also a greater incentive for freeriding behavior (Bauch and Earn 2004; Ibuka et al. 2014; Vietri et al. 2012). The relative comfort of wealth and a lack of vaccine-preventable diseases gives people in wealthier countries the luxury to question the motives of institutions, politicians, and vaccine effectiveness without the more immediate threat of disease epidemics (Daly 2019; Gallup 2019; MacDonald and the SAGE Working Group 2015). A meta-analysis of parental decisions to delay or forego childhood vaccinations finds that vaccine hesitant parents tend to believe that vaccines are unsafe or ineffective, and that the diseases they prevent are both uncommon and mild (Brown et al. 2010). Weakened confidence in vaccines could also be used to justify complacency. People have a tendency to selectively accept information that comports with prior beliefs or desires - confirmation bias - in order to remedy cognitive dissonance (Kahan 2017; Kunda 1990; Taber and Lodge 2007). Therefore, if governments or institutions push vaccines onto a population low in government or institutional 
trust - and if the vaccines at face value seem unnecessary - people may become less trusting of country governments and medical institutions.

In summary, the Out of Sight hypothesis potentially explains the positive relationship between country wealth and vaccine skepticism. Improved public health systems, greater education, and the enactment of health policies have all been able to greatly lower the level of communicable disease in the population via higher vaccination rates. Since disease rates are lowered and communicable diseases have become a "thing of the past," some members of the population are less willing to see the immediate value of vaccination and become skeptical. Skepticism can then become triggered by country-level factors, such as scandals (Larson et al. 2016). Therefore, the Out of Sight hypothesis posits the following:

Alternative Hypothesis (Hypothesis 2): Vaccine skepticism should be negatively correlated with levels of vaccine-preventable diseases.

If true, under this hypothesis the opposite should also occur; once disease becomes prominent in the minds of the populace, vaccine skepticism should go down as the need for the benefits of vaccines are more obvious, immediate, and apparent.

\section{Analytical Strategy}

To test our expectations, we use multi-level modeling (MLM) to model individual survey respondents' attitudes toward vaccines as a function of both respondent-level characteristics (e.g., attitudes toward scientific and government institutions) as well as contextual, country-level factors (e.g., development, internet access, and the prevalence of communicable disease in that country). 
We then examine the interaction between these two sets of predictors; e.g., to investigate whether or not people who are the most distrusting of scientific institutions, in areas with greater internet access, are more likely to hold vaccine skeptic attitudes (Hypothesis $1 b$ ).

The use of MLM is advantageous because, in addition to the respondent and country-level fixed effects listed above, these models also account for possible correlated errors across countries by including random effect country-level parameters. We estimate these models using the xtmixed Stata 15 command suite, which is a mixed multi-level linear regression framework.

Specifically, we expect to have evidence for our hypotheses if the following conditions are met. First, country level internet accessibility should be positively associated with vaccine skepticism (Online Accessibility or Hypothesis 1a), as predicted by the discussion above. Second, under the alternative hypothesis (Out of Sight or Hypothesis 2), a higher number of country-level, vaccine-preventable communicable dis- eases should be negatively associated with vaccine skepticism. Finally, if either factor is truly responsible for the relationship between wealth and skepticism, we also expect the effect of country-level development should decrease in substantive size (and perhaps fall out of significance) when these more proximal explanations are entered into the model.

We also provide an additional test of the Out of Sight hypothesis by examining vaccine skepticism levels in the American public during the COVID-19 pandemic in the United States. Although this additional analysis is limited in its scope, it does provide a test of how people react when a communicable disease suddenly and unexpectedly becomes salient and prevalent in a society. In other words, it shows an instance where the public is obviously aware of the threat of a communicable disease. If vaccine skepticism levels are relatively low during the 
pandemic, then the Out of Sight hypothesis is supported; if they are moderate to higher during the pandemic, then this hypothesis is not supported.

\section{Data \& Measures}

\section{Data}

Data for this study come from the 2018 Wellcome Global Monitor (WGM) survey. Gallup, on behalf of WGM, surveyed N = 149,014 individuals across 144 countries (reflecting about $99 \%$ of the planet's population). Surveys were conducted either face-to-face or over the phone in each country, in the language or languages most commonly spoken in that country. All sub-samples contained at least 1,000 complete interviews, with the exception of Haitiand Iceland (which had only 500 each). Full information about the study's sampling procedures, interview methods, and the languages used to administer the study in each country can be found in Table 2.B in Appendix A of the WGM Methodology Guide (http://doc.ukdataservice.ac.uk/doc/8466/mrdoc/pdf/8466appendixamethodology.pdf).

All 144 sub-samples included in the WGM data set are probability-based and nationally representative within countries. To adjust for unequal probabilities of selection, non-response within country sub- samples, and to ensure national representativeness on age, gender, educational attainment, and socio- economic status, all data are weighted using the PROJWT variable provided by Gallup. For additional information, please consult Appendix A in the WGM Methodology Guide.

\section{Measures}

\section{Vaccine Skepticism}


The key outcome variable in our analysis is a measure of the extent to which individual survey respondents hold vaccine skeptic beliefs. We measure vaccine skepticism by averaging scores across three vaccine belief questions administered in the WGM data. Respondents were asked the extent to which they agree or disagree with following statements; (1) "vaccines are important for children to have," (2) "vaccines are safe," and (3) "vaccines are effective." WGM recorded these responses using (branched) five-point Likert scales; ranging from Strongly Agree to Strongly Disagree.

These three items formed an internally consistent scale $(\alpha=0.76)$, which we recoded to range from 0 (low skepticism) to 1 (high skepticism). Additional information about these items can be found in the Appendix/Supplementary Materials.

\section{Country-Level Explanatory Variables}

Three country-level factors are key for testing our hypotheses. The first is economic development. We measure development using four standard country income level indicators from the World Bank; denoting whether countries are low, lower middle, upper middle, or high income (with low income countries serving as the baseline in our subsequent analyses). These codes are included in the publicly available WGM data, and are current as of 2018.

Additionally, some might raise concern about our of country-level economic development measures. The ordinal World Bank classifications we use have the benefit of detecting potential non-linearities in the effect of income on vaccine skepticism. For example, if vaccine skepticism is uniquely high in the highest wealth countries, we might expect that lower- and middle-income countries are more similar to one another than they are different from higher income countries; 
implying a potentially non-linear effect. Still, we recognize that an ordinal wealth measure could obscure important differences across countries, and potentially make it more difficult to detect an effect of wealth on vaccine skepticism. To remedy this, we re-estimated all models presented in Table 1 using an interval measure of 2017 per capita Gross National Income (see: Table S1 in the Supplement). We again find little evidence in favor of the idea that country-level wealth is associated with vaccine skepticism, once we account for internet connectivity rates.

The next factor, necessary to test the Out of Sight hypothesis, is country-level per capita vaccine-preventable disease prevalence. The World Health Organization (WHO) has kept track of disease prevalence for several vaccine-preventable communicable diseases, for over four decades. The WHO's Global Health Observatory data repository includes disease contraction statistics for several vaccine- preventable and communicable diseases; including measles, mumps, rubella, diptheria, polio, tetanus, and yellow fever (http://apps.who.int/gho/data/node.main.170?lang=en).

To measure disease prevalence, we first summed up the total number of cases observed within each country, across all seven diseases, over the previous decade. Since the countries included in WGM data vary widely in population size, we then divided this number by the total population of each country to obtain the per capita disease prevalence rate. Finally, for consistency with how we measure all other explanatory variables in our model, we standardized scores on this variable to range from 0 (lowest observed per capita disease prevalence) to 1 (highest observed per capita disease prevalence).

Finally, the key explanatory variable necessary to test the Online Accessibility hypothesis is country- level internet accessibility. We use internet accessibility as a proxy for online misinformation for two reasons. First, there are no measures of misinformation accessibility at the country or individual level for more than a handful 
of countries. Even large-N cross-national measures such as social media use as a proxy can be difficult to find because of the variety of social media platforms used across different countries. Second, internet accessibility for the entire country is able to capture the overall misinformation environment; someone may adopt misinformation through direct online access, and then spread that misinformation in face-to-face interactions with friends, family, co-workers, and so on. It is for this reason that we include Hypothesis $1 b$ : not all people with internet access, or who are around others with internet access, will seek out or adopt misinformation. Rather, misinformation adoption is more likely among those who are psychologically more likely to reject scientific and medical misinformation.

Given this, we measure internet access by merging in World Bank data on the percentage of people living in each country who report having used the internet from any location, and on any device - in the past three months. These figures are current as of 2018, and additional information about them can be found on the World Bank's website (https://data.worldbank.org/indicator/IT.NET.USER.ZS).

\section{Individual-Level Explanatory Variables}

In addition to the country-level factors listed above, our models control for a diverse set of individual-level factors that could alternatively explain why some people hold vaccine skeptic views. First, we control for respondents' levels of trust in public health relevant institutions, as both trust in government and scientific expertise have been shown to be associated with a decreased likelihood of endorsing both vaccine-related misinformation and misinformation in general (Miller et al. 2016; Motta 2018; Stecula et al. 2020). We included measures of trust in (1) doctors and nurses, (2) charitable organizations and non-government organizations, and (3) one's national government. Respondents were asked whether they trust each 
institution "a lot," "some," "not much," or "not at all." For ease of interpretation, and because of the relatively few respondents who are very low in trust of these experts, we recoded each of these variables into binary indicators of whether or not respondents hold a lot of trust in each institution.

Next, because some may view vaccines (and the process of inoculation) as a threat to traditional morals (e.g., the desire for moral and bodily purity; Callaghan et al. 2019; Clifford and Wendell 2016), which may be tied to religious views (Haidt 2012), we also control for how much respondents reported a conflict between science and their faith. Respondents were asked whether or not science has "ever disagreed with the teachings of [their] religion" (a binary yes/no choice question). We keyed this variable such that respondents who answered yes to this question received a score of 1 , and all others earned a score of 0 .

Additionally, we control for a wide range of demographic factors that could shape vaccine attitudes. Our models include binary indicators of whether survey respondents are parents (vs. not parents), women (vs. men or non-binary), employed (vs. unemployed, retired, disabled, etc.), live in an urban area (vs. rural), and whether they report having college-level experience with any sciencerelevant coursework (vs. either going to college and not having this experience, or not attending college at all). We also account for respondents' household income (binary quintile indicators, calculated within country by the World Bank, with the bottom $20 \%$ serving as the reference category), and age (standardized to range from zero to one). Additional information about all of these basic demographic controls can be found in the Appendix/Supplementary Materials.

\section{Results}


We begin with an illustration of the conceptual and empirical puzzle driving our study. Figure 1 presents country-level mean scores on the vaccine skepticism index (hollow blue circles). The scores are grouped together by economic development, and fit with a locally weighted regression line.

\section{[Insert Figure 1 here]}

Figure 1 suggests a strong positive relationship between economic development and vaccine skepticism, at the country level. As the locally weighted regression line indicates, countries that are more developed economically tend to produce higher average levels of vaccine skepticism (Spearman's rho $=0.52$ ).

Column 1 in Table 1 presents the results of our baseline mixed multilevel model; regressing vaccine skepticism on binary indicators of each economic development level. Since all variables are keyed to range from 0-1, parameter estimates can be interpreted as the percent change in skepticism, moving from the minimum to maximum value on that variable. Recall that, in addition to the fixed effect of economic development, these models include country-level random effects.

[Insert Table 1 here]

Table 1, Column 2 provides strong support for the main Online Accessibility hypothesis. In Column 2, we swap the indicator of disease prevalence for the percent of each country's population with internet access, as of 2018. Internet accessibility is associated with a substantively large (14 point) and statistically significant $(\mathrm{p}<0.05)$ increase in vaccine skepticism. Moreover, all indicators of economic development drop from significance when internet access is added to the model. 
The effect of internet access holds when we add various individuallevel and country-level controls to the model, in Column 4. Several individual-level factors - like trust in doctors $(\beta=-0.06, \mathrm{p}<0.05)$, country government $(\beta=-0.02, \mathrm{p}<0.05)$, and non-government medical institutions $(\beta=-0.03, \mathrm{p}<0.05)-$ are associated with decreased vaccine skepticism. Moreover, experiencing conflict between science and one's faith is associated with a slight (but nevertheless statistically significant; $\beta=0.02, \mathrm{p}<0.05$ ) increase in vaccine skepticism. Nevertheless, these factors fail to explainaway the relationship between internet access and vaccine skeptic beliefs.

Conversely, Column 2 in Table 1 tests the Out of Sight hypothesis; i.e., that people who live in less developed countries have more experience with vaccine-preventable communicable disease than people in more developed countries, and are therefore more supportive of efforts to vaccine the public. To test this, we add our indicator of per capita vaccinepreventable communicable disease contraction rates over the past ten years, in each country, to the baseline model in Column 1.

Table 1 provides little support of the Out of Sight hypothesis. Per the protocol outlined in our Analysis Plan, we do not find that the inclusion of communicable disease contraction rates "explains away" the effect of economic development. In fact, and in sharp contrast to our expectations, we actually document a positive effect of disease prevalence on vaccine skepticism $(\beta=$ 0.07, $\mathrm{p}<0.05)$. Therefore, we find evidence of the Misinformation Availability hypothesis but not for the Out of Sight hypothesis.

Given the correlational nature of the data, we hesitate to offer a post hoc explanation of why this effect exists. However, some might speculate that this unexpected effect could be better explained by a reverse causal 
account; such that countries with higher levels of vaccine skepticism tend to have higher-levels of vaccine-preventable disease, precisely because fewer individuals in those populations believe that vaccines are safe, and may refuse to vaccine themselves (or their children) as a result.

While Columns 2 and 4 in Table 1 offer strong support for the Online Accessibility hypothesis, we are nevertheless unable to actually observe the behavior that we assume to be responsible for this phenomenon, given that there is no measure of Online Accessibility available for more than a handful of countries. However, we can at least offer a series of interactive tests to probe this hypothesis further. If it is the case that people in highaccess countries are using the internet to consume misinformation about vaccines, then we should expect to observe a negative and statistically significant interaction between internet access and trust in medical and government institutions - both of which have been observed to be linked to vaccine misinformation in countries like the U.S. The types of people most likely to want to consume anti-vaccine misinformation online should be more likely to do so in countries where they have a comparatively better ability to do so, and should therefore exhibit higher levels of vaccine skepticism.

Columns 5-7 in Table 1 interact the previously-mentioned measures of trust in doctors, medical NGOs, and country governments, with internet access. To avoid collinearity concerns, we estimate each interaction in a separate model. Further, to facilitate the substantive interpretation of the interactive coefficients listed in Table 1, Figure 2 plots linear predictions on the vaccine skepticism scale across levels of internet access, for people who exhibit high versus low levels of trust toward each group. Consistent 
with our expectations $(H 1 b)$, people who express low trust in doctors $(\beta$ $=-0.11, \mathrm{p}<0.05)$ and medical NGOs $(\beta=-0.05, \mathrm{p}<0.05)$ are significantly more likely to be vaccine skeptical if they have greater internet access. However, while the interaction between government trust and internet access is correctly signed $(\beta=-0.02)$, the effect fails to attain or approach conventional levels of significance $(p>0.10)$.

[Insert Figure 2 here]

As Figure 2 illustrates, vaccine skepticism increases sharply for those who express low trust in the two medically-focused variables (doctors and NGOs), at higher levels of internet access. In the highest access countries, those with low levels of trust in doctors score nearly $12 \%$ higher on the vaccine skepticism scale (0.26) than those who express high levels of trust (0.14). At the lowest observed levels of internet access, however, people who express lower trust in doctors do tend to express higher levels of skepticism $(0.05)$ than those who are comparatively more trusting $(0.04)$, but these differences are substantively small and fail to attain statistical significance.

Overall, we believe that these results provide compelling support for the Online Accessibility hypothesis. Internet access is strongly associated with negative attitudes toward vaccines, and explains away the effect of economic development on vaccine skepticism. Moreover, we find that the types of people we would expect to consume anti-vaccine misinformation online are more likely to hold vaccine skeptic views. Critically, though, this only appears to be the case in countries that have comparatively greater internet access. Although we lack the ability to observe respondents encountering 
misinformation online, this pattern of results is consistent with the mechanisms that we expect to underlie this effect.

\section{Vaccine Attitudes and the U.S. COVID-19 Outbreak}

As mentioned above, to provide an additional test of the Out of Sight Hypothesis, we provide a case study of vaccine skepticism during a disease outbreak in U.S. in April 2020. We use this case because the U.S. had the most confirmed cases and highest fatality rate of COVID-19 at the time, and for all subsequent months to date (Dong et al. 2020). Other developed countries that experienced sharp spikes in COVID-19 cases, such as Italy, saw a drop in such cases. Our above analysis lacks a test of disease familiarity; the COVID-19 pandemic is highly salient to the vast majority of people in the U.S., and has been for a sustained period, thereby providing a strong test for the Out of Sight hypothesis. If this hypothesis is correct, such a scenario should lead to sharply decreased vaccine skepticism, compared to before the outbreak, as the immediate and looming threat of disease is very much "in-sight."

At the same time, however, the pandemic has greatly increased feelings of uncertainty and anxiety (Keeter 2020). Uncertainty and anxiety will cause people to seek out and adopt new information (Albertson and Gadarian 2015). If the information environment contains misinformation, then misinformation seeking and adoption will be heightened. In addition, more people in lockdown will likely lead them to use social media more. For example, Facebook and Instagram usage increased significantly in countries hardest hit by the virus; Italy saw a $70 \%$ increase in usage in late March 2020, for instance (Schultz and 
Parikh 2020). Furthermore, studies have found that COVID-19

misinformation surrounding vaccines is already widespread on social media in various countries, including in the case study here (the U.S.) (French et al. 2020), as well as in locations such as Nigeria where a whopping $80 \%$ of people use social media to get COVID-19 information (Enitan et al. 2020). Consequently, vaccine skepticism adoption levels may be at least the same as before the outbreak, or even increased.

To study vaccine attitudes and vaccine misinformation endorsement among Americans before and during the COVID-19 pandemic, we use original survey data from three cross-sectional samples of nationally diverse samples of American adults. The surveys were fielded in midApril $2020(\mathrm{~N}=493)$, mid-August $2019(\mathrm{~N}=825)$, and Summer $2018(\mathrm{~N}$ $=7,019)$, and respondents were recruited via Lucid Theorem, an online opt-in panel service. Though these surveys are not nationally representative, Lucid uses quota sampling to ensure demographic makeup close to nationally representative on factors like race, age, sex, household income, and Census region. Demographic and experimental findings using Lucid resemble U.S. Census demographic benchmarks, and samples from Lucid are more representative than traditional convenience samples on various demographic, political, and psychological factors (Coppock and McClellan 2019). Researchers in public health and health politics have also previously published papers using Lucid data (e.g., Callaghan et al. 2019; Lunz Trujillo et al. 2020).

Furthermore, for each survey we also weight the data according to race, age, education level, sex, and income level using the Stata 15 svywgt command set, which employs propensity scores. Information on sample 
demographics (weighted and unweighted) compared to national benchmarks are in the Appendix/Supplementary Materials. Finally, since we compare the percent of respondents providing responses to the same questions from different Lucid samples (and not across different platforms or sample sources), any sample idiosyncrasies specific to Lucid should not account for differences in responses between samples.

In the 2020 survey, we measured respondents' degrees of overall vaccine skepticism. This survey measurement is similar to the vaccine skepticism measure used in the above analyses. Respondents were asked, "How much do you think the following characteristics apply to vaccines in general?" Respondents then saw the characteristics "Safe", "Effective", and "Important". For each characteristic, respondents could choose either "Not at all", "A little", "A moderate amount", or "Quite a bit". These three items were then re-scaled from zero to one and averaged and combined into a single vaccine skepticism scale. These items have a scale reliability coefficient of 0.91 and an average inter-item variance of 0.07 . In addition, the 2020 survey also asked respondents about support for a potential COVID-19 vaccine using the question, "Would you be willing to get vaccinated against COVID19, once a vaccine is available?". Response options include "Yes," "No," "I already got COVID-19, but if I hadn't, I would”, and, “I already got COVID-19, but if I hadn't, I would not". Although the data for this last question is limited to a single survey, and thus lacks a pre-outbreak baseline, it is still useful to examine. Finally, for both the 2020 and the 2018 survey, we also asked whether respondents agreed with the statement that "Childhood vaccines should be mandatory." Response options included a seven-point Likert scale ranging from "Strongly agree" to "Strongly disagree." This question provides a sense of pro-vaccination policy endorsement, which relates to levels of vaccine skepticism in the public. 
[Insert Figure 3 here]

Figure 3 above provides preliminary evidence that vaccineskeptical attitudes have stayed at similar levels - or even increased - since before the COVID-19 outbreak. In 2017, the mean score was 0.15 on a zero to one scale $(95 \% \mathrm{CI}=(0.14,0.16))$; in 2020 , the mean score was $0.25(95 \% \mathrm{CI}=(0.22,0.28))$. Further, opposition to mandatory vaccinations for children has remained steady from 2018 to 2020 ; $9 \%$ of respondents in both the 2018 and the 2020 Lucid surveys did not agree that childhood vaccinations should be mandatory.

It is also useful to determine whether people are willing to receive a vaccine against COVID-19. Although there is no baseline of comparison for this metric, it is nonetheless indicative of overall vaccine skepticism. Using the April 2020 Lucid data, 23\% of respondents said they would not get the vaccine for COVID-19 (or, that they had already gotten COVID-19, but if they had not, they would not get the vaccine). This finding has been echoed in subsequent studies, with Americans remaining at the same level of support for the COVID-19 vaccine or becoming even more adverse to it; studies from July 2020 find that only two thirds to one half of Americans plan on getting the coronavirus vaccine once it becomes available (Cornwall 2020; O'Keefe 2020).

Furthermore, we asked respondents separate questions on whether they think vaccines are safe, effective, and important to measure vaccine skepticism in the sample. Respondents indicated if they thought each of these aspects generally described vaccines "quite a bit," "a moderate amount," "a 
little bit" or "not at all." The averaged of these three measures created a scale of vaccine skepticism; those less than 0.5 on this standardized scale we considered vaccine skeptical, which came out to $19 \%$ of the sample. Among that $19 \%, 62 \%$ said they would not get vaccinated against COVID-19. Conversely, for those non-vaccine skeptical, 15\% said that they would not get the COVID-19 vaccine.

Taken together, these results suggest that - inconsistent with the Out of Sight Hypothesis - vaccine skepticism has, if anything, increased during a salient and impactful pandemic, i.e., during a time when infectious disease is on everyone's mind. Furthermore, reluctance to commit to getting a COVID19 vaccine, once it becomes available, further corroborates this point. Rather, vaccine skepticism has either remained at approximately the same levels as before the pandemic, or perhaps increased slightly. Although this data is limited to just one highly-developed country, it - taken in conjunction with the above analysis - casts doubt on the alternative Out of Sight hypothesis.

\section{Discussion and Conclusion}

Vaccine skepticism tends to be more prevalent in wealthier countries, compared to inhabitants of middle- income or poorer countries. However, it is unclear why this is the case. We find strong support for the Online Accessibility hypothesis, or that internet availability explains this discrepancy, particularly for those individuals most likely to endorse misinformation (i.e., those who are less trusting of relevant experts and organizations). In fact, when including internet access into the Full model in Table 1 , the relationship between country wealth and vaccine skepticism is no longer significant. 
Furthermore, we find no evidence of the alternative hypothesis - that low rates of communicable disease correlates with vaccine skepticism. Instead, the relationship between vaccine preventable diseases and country wealth is positively correlated. Similarly, in the U.S. anti-vaccine sentiment of various kinds has slightly increased in the face of a highly salient and widespread pandemic.

That said, this study does have some limitations. Although the data is nationally representative across 144 countries, it is nevertheless crosssectional data. Therefore, we cannot be certain that internet access causes increased levels of vaccine skepticism, as our theoretical discussion suggests. Panel data would enable us to study how changes in internet access over time influence vaccine attitudes, and would give us significantly more leverage in making causal claims.

Additionally, our measures of internet accessibility and disease prevalence are measured at the country level. We recognize that both factors are unlikely to be constant within countries. For example, although the U.S. has high levels of internet accessibility, some rural regions of the country do not have access to high-speed internet. Consequently, we welcome efforts to study the spread and cross-national political consequences of misinformation online using sub-national data.

Despite these limitations, understanding why heightened levels of vaccine skepticism occurs in wealthier countries matters a great deal. In light of the COVID-19 pandemic, we have experienced how an infectious disease outbreak can have major consequences for the economy, our health, our economy, our politics, and our daily lives. Measures taken to reduce the spread of COVID-19 will likely stay in 
place until a vaccine has been developed. Yet, if a significant portion of the population remains skeptical of vaccines, then the spread of COVID19 may not be sufficiently curbed. Future studies should hone in on the prevalence of vaccine misinformation in the face of such a clear and present danger.

Vaccine misinformation, and finding steps to reduce it, also matters because such misinformation poses a threat to support for vaccine policies, regardless of uptake. Additionally, a population that currently vaccinates may not continue to do so in the future, and active discouragement of vaccination through the spread of misinformation (and indirectly via less restrictive policy preferences) can jeopardize the high vaccination rates in wealthier countries. In addition, herd immunity can be compromised even with fairly high vaccination rates; vaccination rates as high as $93-95 \%$ can open enough of a window for measles to return, for example (van Boven et al. 2010). This means that even a small number of vaccine skeptical citizens has the potential to cause disease outbreaks. Finally, vaccine misinformation also poses a threat to good governance; populist leaders appear particularly apt to use anti-vaccine policies and rhetoric to appeal to potential voters, since the anti-elitism of populism is appealing to the vaccine skeptical, who are mistrustful of medical experts and institutions.

Finally, misinformation threatens not only vaccination attitudes, but also attitudes toward other scientific, political, and health-related topics. The findings here have implications for other types of misinformation and anti-science attitudes more broadly. Misinformation changes collective preferences in the mass public, negatively affecting 
policy outcomes (Fowler and Margolis 2013; Kuklinski et al. 2000). For

this reason, it is imperative that scholars, as well as science and health

communicators, devise strategies for stemming the flow of misinformation

and correcting misinformed attitudes. Various scholars have been working

on ways to correct such misinformed attitudes (Bode and Vraga 2015;

Lunz Trujillo et al. 2020; Nyhan and Reifler 2015; Nyhan et al. 2014),

though more work is needed to create better methods and strategies

toward this end.

\section{References}

Aslam M and Kingdon GG (2012) Parental education and child health - understanding the pathways of impact in Pakistan. World Development, 40(10), 2014-2032.

Albertson B and Gadarian S (2012) Anxious Politics: Democratic Citizenship in a Threatening World. Cambridge: Cambridge University Press.

Bauch CT and Earn DJ (2004) Vaccination and the theory of games. Proceedings of the National Academy of Sciences, 101(36), 13391-13394.

Bean S (2011) Emerging and continuing trends in vaccine opposition website content. Vaccine, 29(10), 1874-1880.

Betsch C, Bohm R and Chapman GB (2015) Using behavioral insights to increase vaccination policy effectiveness. Policy Insights from the Behavioral and Brain Sciences, 2(1), 6173.

Betsch C and Sachse K (2012) Dr. Jekyll or Mr. Hyde? (How) the Internet influences vaccination decisions: Recent evidence and tentative guidelines for online vaccine communication. Vaccine, 25(30), 3723-3726.

Bode L and Vraga EK (2015) In related news, that was wrong: The correction of misinformation through related stories functionality in social media. Journal of Communication, 65(4), 619-638.

Boseley S (2018) Measles cases at highest for 20 years in Europe, as anti-vaccine movement grows. The Guardian Online. 21 December 2018. Available from: https://www.theguardian.com/world/2018/dec/21/measles-cases-at-highest-for-20years-in- europe-as-anti-vaccine-movement-grows (accessed 4 December 2020).

Buncombe A (2018) Trump claims vaccines and autism are linked but his own experts vehemently disagree. The Independent. 2 May 2018. Available from: https://www.independent.co.uk/news/world/americas/trump-vaccines-autism-linksanti-vaxxer- us-president-false-vaccine-a8331836.html (accessed 8 Jan 2020).

Callaghan T, Motta M, Sylvester S, Lunz Trujillo K and Blackburn CC (2019) Parent psychology and the decision to delay childhood vaccination. Social Science \& Medicine, 238, 112407. 
Carpiano RM and Fitz NS (2017) Public attitudes toward child undervaccination: A randomized experiment on evaluations, stigmatizing orientations, and support for policies. Social Science \&Medicine, 185, 127-136.

Choi S (2015) The two-step flow of communication in Twitter-based public forums. Social science computer review, 33(6), 696-711.

Clarke S (2007) Conspiracy theories and the Internet: Controlled demolition and arrested development. Episteme, 4(2), 167-180.

Clifford S and Wendell DG (2016) How disgust influences health purity attitudes. Political Behavior, 38(1), 155-178.

Collange F, Fressard L, Pulcini C, Sebbah R, Peretti-Watel P and Verger P (2016) General practitioners' attitudes and behaviors toward HPV vaccination: A French national survey. Vaccine, 34(6), 762-768.

Coppock A and McClellan OA (2019) Validating the demographic, political, psychological, and experimental results obtained from a new source of online survey respondents. Research \& Politics, 6(1), 2053168018822174.

Cornwall W (2020) Just 50 percent of Americans plan to get a COVID-19 vaccine. Here's how to win over the rest. Science Magazine. 30 June 2020. Available from: https://www.sciencemag.org/news/2020/06/just-50-americans-plan-get-covid-19vaccine-here-s-how-win-over-rest (accessed 20 August 2020).

Daly J (2019) Wealthier countries have less faith in vaccines, survey finds. The Journal. 19 June 2019. Available from: https://www.thejournal.ie/france-low-level-of-trust-invaccines-study- 4688605-Jun2019/ (accessed 4 December 2019).

Dong E, Du H, and Gardner L (2020) An interactive web-based dashboard to track COVID-19 in real time. The Lancet Infectious Diseases. DOI: https://doi.org/10.1016/S1473-3099(20)30120-1

Enitan SS., Oyekale AO, Akele RY, Olawuyi KA, Olabisi, EO and Nwankiti AJ (2020) Assessment of Knowledge, Perception and Readiness of Nigerians to Participate in the COVID-19 Vaccine Trial. International Journal of Vaccine Immunization, 4(1).

Ennals R, Trushkowsky B and Agosta JM (2010) Highlighting disputed claims on the web. In Proceedings of the 19th international conference on World wide web, 341-350. New York, NY: ACM.

Fowler A and Margolis M (2013) The political consequences of uninformed voters. Electoral Studies, 30, 1-11.

French J, Deshpande S, Evan, W and Obregon R (2020) Key Guidelines in Developing a PreEmptive COVID-19 Vaccination Uptake Promotion Strategy. International Journal of Environmental Research and Public Health, 17(16), 5893.

Gallup (2019) Wellcome Global Monitor Report: How does the world feel about science and health? Available from https://wellcome.ac.uk/sites/default/files/wellcome-global-monitor2018.pdf.

Haidt J(2012) Therighteousmind: Why goodpeoplearedivided bypoliticsandreligion. Vintage.

Hershey JC, Asch DA, Thumasathit T, Meszaros J and Waters VV (1994) The roles of altruism, free riding, and bandwagoning in vaccination decisions. Organizational behavior and human decision processes, 59(2), 177-187.

Hilbert M, Vásquez J, Halpern D, Valenzuela S and Arriagada E. (2017) One step, two step, network step? Complementary perspectives on communication flows in Twittered citizen protests. Social science computer review, 35(4), 444-461.

Hornsey MJ, Harris EA and Fielding KS (2018) The psychological roots of antivaccination attitudes: A 24-nation investigation. Health Psychology, 37(4), 307.

Ibuka Y, Li M, Vietri J, Chapman GB and Galvani AP (2014) Free-riding behavior in vaccination decisions: an experimental study. PloS one, 9(1), e87164.

Jolley D and Douglas KM (2014) The effects of anti-vaccine conspiracy theories on vaccination intentions. PloS one, 9(2), e89177.

Joslyn MR and Sylvester SM (2017) The determinants and consequences of accurate beliefs about childhood vaccinations. American Politics Research, 47(3), 628-649.

Joslyn MR and Sylvester SM (2018) Why educated Republicans are still less likely to trust child- hood vaccinations than educated Democrats. USApp-American Politics and PolicyBlog. Available from: http://blogs.lse.ac.uk/usappblog/2018/04/10/whyeducated-republicans-are-still-less-likely- to-trust-childhood-vaccinations-thaneducated-democrats/ (accessed 29 November 2019).

Kahan DM (2017) 'Ordinary science intelligence': A science-comprehension measure for study of risk and science communication, with notes on evolution and climate change. 
Journal of Risk Research, 20(8), 995-1016.

Kata A (2010) A postmodern Pandora's box: Anti-vaccination misinformation on the Internet. Vaccine, 28(7), 1709-1716.

Kata A (2012) Anti-vaccine activists, Web 2.0, and the postmodern paradigm-An overview of tactics and tropes used online by the anti-vaccination movement. Vaccine, 30(25), 3778-3789.

Katz E and Lazarsfeld PF (1955) Personal Influence: the Part Played by People in the Flow of Mass Communications.

Keeter S (2020) People financially affected by COVID-19 outbreak are experiencing more psychological distress than others. Pew Research Center, 30 March 302020. Available from: https://www.pewresearch.org/fact-tank/2020/03/30/peoplefinancially-affected-by-covid- 19-outbreak-are-experiencing-more-psychologicaldistress-than-others/ (accessed 15 April 2020).

Kennedy J (2019) Populist politics and vaccine hesitancy in Western Europe: an analysis of national- level data. European journal of public health, 29(3), 512-516.

Klofstad C, Uscinski JE, Connolly JM and West JP (2019) What drives people to believe in Zika conspiracy theories?. Palgrave Communications, 5(36). doi:10.1057/s41599-0190243-8

Kraft PW, Lodge M and Taber CS (2015) Why people "don't trust the evidence" motivated reason- ing and scientific beliefs. The ANNALSofthe American Academy of Political and SocialScience, 658(1), 121-133.

Kuklinski JH, Quirk PJ, Jerit J, Schwieder D and Rich RF (2000) Misinformation and the currency of democratic citizenship. Journal of Politics, 62(3), 790-816.

Kunda Z (1990) The case for motivated reasoning. Psychological Bulletin, 108, 480-498.

Larson HJ (2018) The state of vaccine confidence. The Lancet, 392(10161), 2244-2246.

Larson HJ, Cooper LZ, Eskola J, Katz SL and Ratzan S (2011) Addressing the vaccine confidence gap. The Lancet, 378(9790), 526-535.

Larson HJ, Jarrett C, Eckersberger E, Smith DM and Paterson P (2014) Understanding vac- cine hesitancy around vaccines and vaccination from a global perspective: a systematic review of published literature, 2007-2012. Vaccine, 32(19), 2150-2159.

Larson HJ, De Figueiredo A, Xiahong Z, Schulz WS, Verger P, Johnston IG, ... and Jones NS (2016) The state of vaccine confidence 2016: global insights through a 67-country survey. EBioMedicine, 12, 295-301.

Lunz Trujillo K, Motta M, Callaghan T and Sylvester S (2020) Correcting Misperceptions about the MMR Vaccine: Using Psychological Risk Factors to Inform Targeted Communication Strategies. Political Research Quarterly. DOI: https://doi.org/10.1177/1065912920907695.

MacDonald NE and the SAGE Working Group on Vaccine Hesitancy (2015). Vaccine hesitancy: definition, scope and determinants. Vaccine, 33(34), 4161-4.

Merkley E (2019) Anti-Intellectualism, Populism, and Motivated Resistance to Expert Consensus. Public Opinion Quarterly DOI: https://doi.org/10.31219/osf.io/qkd57

Messing S and Westwood SJ (2014) Selective exposure in the age of social media: Endorsements trump partisan sourceaffiliation when selecting news online. Communicationresearch, 41(8), 1042- 1063.

Miller JM, Saunders KL and Farhart CE (2016) Conspiracy endorsement as motivated reasoning: The moderating roles of political knowledge and trust. American Journal of Political Science, 60(4), 824-844.

Motta M (2018) The enduring effect of scientific interest on trust in climate scientists in the United States. Nature Climate Change, 8(6), 485.

Motta M, Callaghan T and Sylvester S (2018) Knowing less but presuming more: Dunning-Kruger effects and the endorsement of anti-vaccine policy attitudes. Social Science \& Medicine, 211, 274- 281.

Nyhan B and Reifler J (2015). Does correcting myths about the flu vaccine work? An experimental evaluation of the effects of corrective information. Vaccine, 33(3), 459464.

Nyhan B, Reifler J, Richey S and Freed GL (2014) Effective messages in vaccine promotion: a randomized trial. Pediatrics, 133(4), e835-e842.

O'Keefe SM (2020) One in Three Americans Would Not Get COVID-19 Vaccine. Gallup News: Politics. 7 August 2020. Available from: https://news.gallup.com/poll/317018/one-three-americans- not-covid-vaccine.aspx (accessed 20 August 2020). 
Poushter J (2016) Smartphone ownership and internet usage continues to climb in emerging economies. Pew Research Center, 22, 1-44.

Prior L (2003) Belief, knowledge and expertise: the emergence of the lay expert in medical sociology. Sociology of Health \& Illness, 25(3), 41-57.

Rammohan A, Awofeso N and Fernandez RC (2012). Paternal education status significantly influ- ences infants' measles vaccination uptake, independent of maternal education status. BMC public health, 12(1), 336.

Rabesandratana T (2019) "France most skeptical about science and vaccines, global survey finds." Science Magazine, 19 June 2019. Available from: https://www.sciencemag.org/news/2019/06/france- most-skeptical-about-science-andvaccines-global-survey-finds (accessed 27 December 2019).

Restrepo-Mendez MC, Barros AJ, Wong KL, Johnson HL, Pariyo G, França GV, ... and Victora CG (2016) Inequalities in full immunization coverage: trends in low-and middle-income countries. Bulletin of the World Health Organization, 94(11), 794.

Schultz A and Farikh J (2020) Keeping Our Services Stable and Reliable During the COVID-19 Outbreak. Facebook (News). 24 March 2020. Available from: https://about.fb.com/news/2020/03/keeping- our-apps-stable-during-covid-19/ (accessed 20 August 2020).

Schwarzer R and Fuchs R (1996) Self-efficacy and health behaviours. In Predicting health behavior: Research and practice with socialcognition models, eds Connor $\mathrm{M}$ and Norman P. Buckingham: Open University Press.

Stecula D, Kuru O and Jamieson KH (2020a) How trust in experts and media use affect acceptance of common anti-vaccination claims. Harvard Kennedy School Misinformation Review, 1(1), https://doi.org/10.37016/mr-2020-007

Stecula D, Kuru O, Albarracin D and Jamieson KH (2020b) Policy Views and Negative Beliefs About Vaccines in the United States, 2019. American Journal of Public Health, https://doi.org/10.2105/AJPH.2020.305828.

Taber CS and Lodge M (2006) Motivated skepticism in the evaluation of political beliefs. American Journal of Political Science, 50(3), 755-769.

Tavris C and Aronson E (2008) Mistakes weremade(butnotbyme): Whywejustifyfoolish beliefs, bad decisions, and hurtful acts. Houghton Mifflin Harcourt.

van Boven M, Kretzschmar M, Wallinga J, O’Neill PD, Wichmann O and Hahné S (2010) Estimation of measles vaccine efficacy and critical vaccination coverage in a highly vaccinated population. Journal of the Royal Society Interface, 7(52), 1537-1544.

Vietri JT, Li M, Galvani AP and Chapman GB (2012) Vaccinating to help ourselves and others. Medical Decision Making, 32(3), 447-458

World Health Organization (WHO) (2019) Ten threats to global health in 2019. Available from: https:/www.who.int/emergencies/ten-threats-to-global-health-in-2019 (accessed 27 Decem- ber 2019). 
Figure 1. Average Levels of Vaccine Skepticism, by Country and Development Level

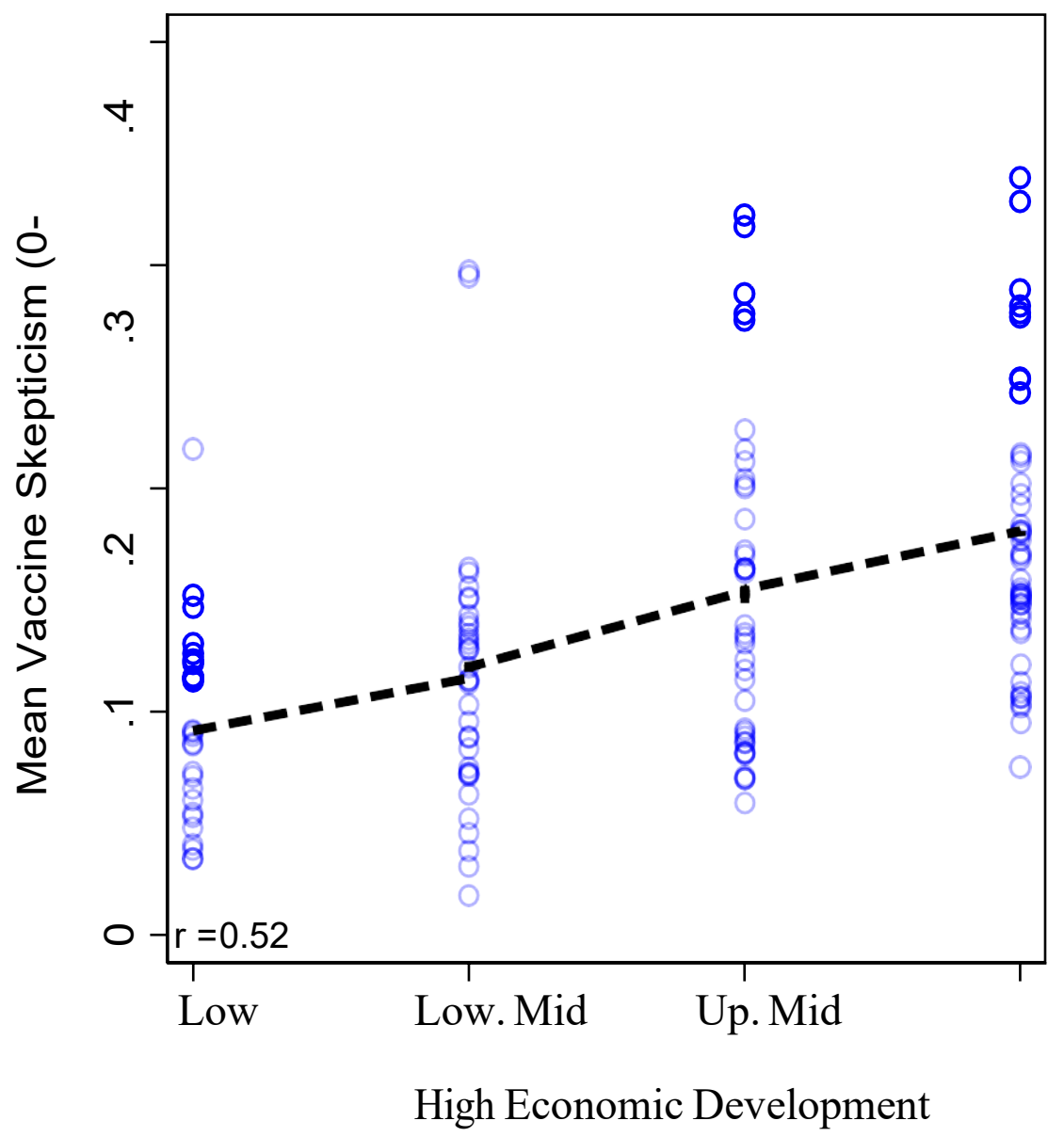

Note. Weighted country level means presented (hollow circles), fit with a locally weighted regression line (bandwidth $=0.60$ ). The lower left-hand corner of the figure shows a Spearman's rank order correlation between economic development and mean skepticism at the country level. 
Figure 2. The Conditional Effect of Internet Access on Vaccine Skepticism
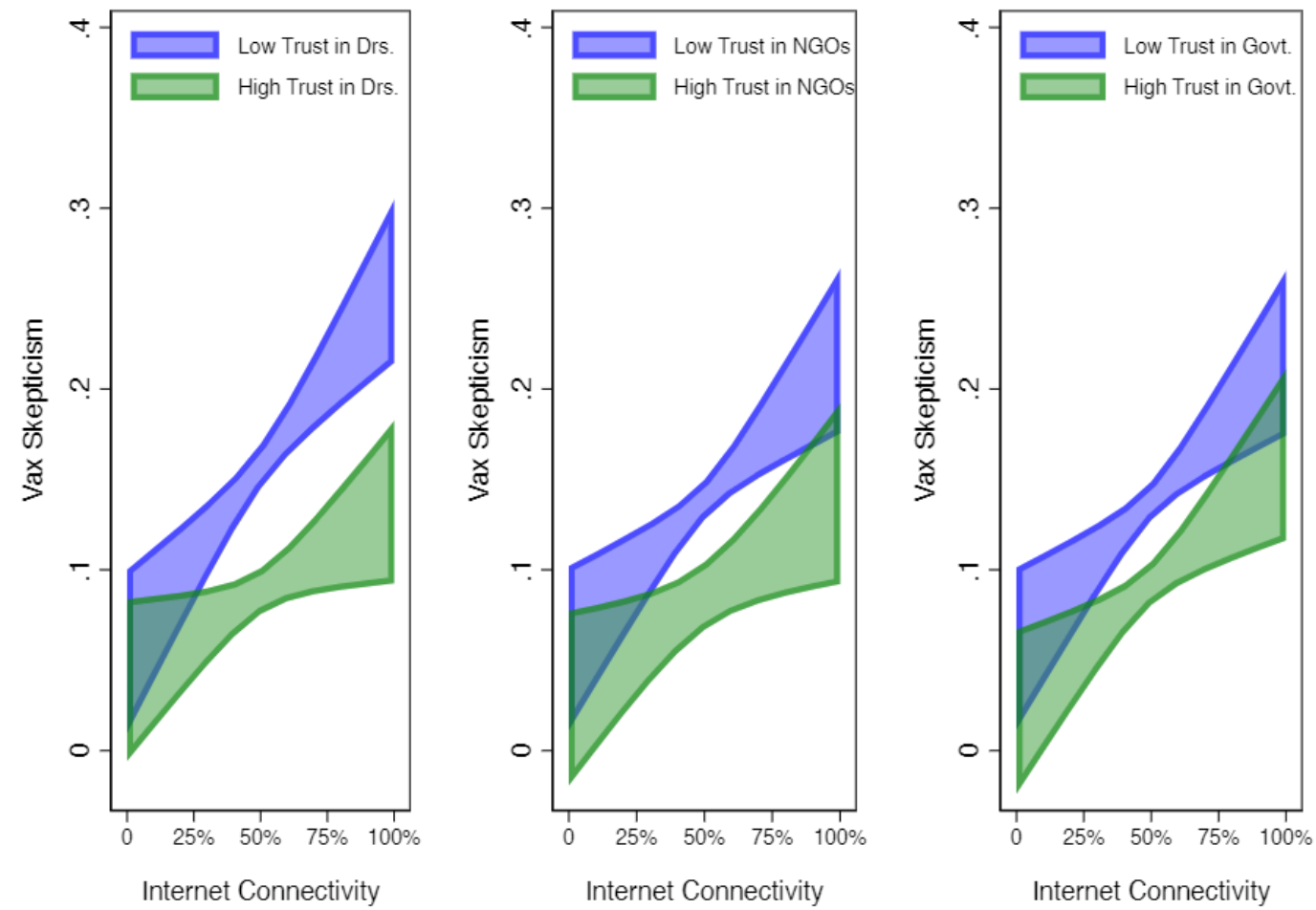

Note. Figure presents the interaction between country-level internet access and (in order) trust in doc- tors, medical NGOs, and country government. Linear predictions are expressed as $95 \%$ confidence interval bands, for people exhibiting high and low levels of trust in each group. Only the interaction between trust in government and internet access fails to attain conventional levels of statistical significance ( $p>0.10$, two-tailed). 
Figure 3. Vaccine Skepticism in the U.S., 2017 versus 2020

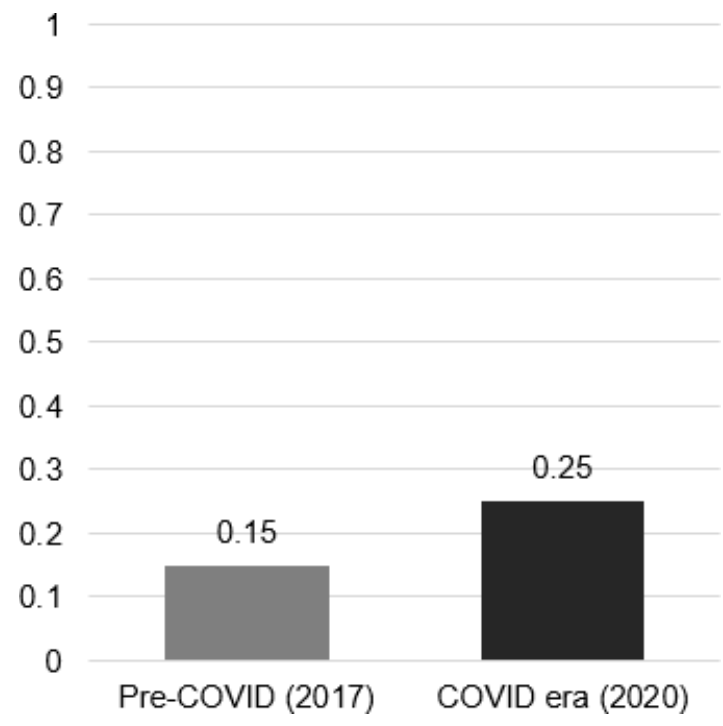

Note. Left side of figure presents the mean vaccine skepticism scale for the entire U.S. sample of the Wellcome Global Monitor data $(\mathrm{N}=983)$. The right side displays the mean vaccine skepticism score for the 2020 Lucid survey $(\mathrm{N}=493)$, which was done on U.S. adults in April 2020. Vaccine skepticism in both surveys is based on how much respondents see vaccines as safe, effective, and/or important. All data is weighted to U.S. population benchmarks. 
Table 1. The Microfoundations of Vaccine Skepticism (Multilevel Linear Models with Country Random FX)

\begin{tabular}{|c|c|c|c|c|c|c|c|}
\hline & Base & + Int. & + Dis & Full & Docs & NGOs & Govts \\
\hline Parent & - & - & - & $\begin{array}{l}-0.00 \\
(0.00)\end{array}$ & $\begin{array}{l}-0.00 \\
(0.00)\end{array}$ & $\begin{array}{l}-0.00 \\
(0.00)\end{array}$ & $\begin{array}{l}-0.00 \\
(0.01)\end{array}$ \\
\hline Female & - & - & - & $\begin{array}{l}-0.00 \\
(0.00)\end{array}$ & $\begin{array}{l}-0.00 \\
(0.00)\end{array}$ & $\begin{array}{l}-0.00 \\
(0.00)\end{array}$ & $\begin{array}{l}-0.00 \\
(0.00)\end{array}$ \\
\hline Age & - & - & - & $\begin{array}{c}-0.05^{* *} \\
(0.02)\end{array}$ & $\begin{array}{c}-0.05^{* *} \\
(0.02)\end{array}$ & $\begin{array}{c}-0.06^{* *} \\
(0.02)\end{array}$ & $\begin{array}{c}-0.06 * * \\
(0.03)\end{array}$ \\
\hline Employed & - & - & - & $\begin{array}{l}-0.00 \\
(0.01)\end{array}$ & $\begin{array}{c}-0.00 \\
(0.01)\end{array}$ & $\begin{array}{c}-0.00 \\
(0.01)\end{array}$ & $\begin{array}{l}-0.00 \\
(0.01)\end{array}$ \\
\hline $20 \% \mathrm{HHI}$ & - & - & - & $\begin{array}{c}0.00 \\
(0.00)\end{array}$ & $\begin{array}{c}0.00 \\
(0.01)\end{array}$ & $\begin{array}{c}0.00 \\
(0.01)\end{array}$ & $\begin{array}{c}0.01 \\
(0.01)\end{array}$ \\
\hline $40 \% \mathrm{HHI}$ & - & - & - & $\begin{array}{l}-0.00 \\
(0.01)\end{array}$ & $\begin{array}{l}-0.00 \\
(0.01)\end{array}$ & $\begin{array}{l}-0.00 \\
(0.01)\end{array}$ & $\begin{array}{l}-0.00 \\
(0.01)\end{array}$ \\
\hline $60 \% \mathrm{HHI}$ & - & - & - & $\begin{array}{l}-0.00 \\
(0.01)\end{array}$ & $\begin{array}{c}0.00 \\
(0.01)\end{array}$ & $\begin{array}{l}-0.00 \\
(0.01)\end{array}$ & $\begin{array}{l}-0.00 \\
(0.01)\end{array}$ \\
\hline $80+\% \mathrm{HHI}$ & - & - & - & $\begin{array}{c}0.00 \\
(0.01)\end{array}$ & $\begin{array}{c}0.01 \\
(0.01)\end{array}$ & $\begin{array}{c}0.01 \\
(0.01)\end{array}$ & $\begin{array}{c}0.01 \\
(0.01)\end{array}$ \\
\hline Urban & - & - & - & $\begin{array}{c}0.00 \\
(0.00)\end{array}$ & $\begin{array}{c}0.00 \\
(0.00)\end{array}$ & $\begin{array}{c}0.00 \\
(0.00)\end{array}$ & $\begin{array}{c}0.00 \\
(0.00)\end{array}$ \\
\hline Coll. Sci Course & - & - & - & $\begin{array}{l}-0.00 \\
(0.01)\end{array}$ & $\begin{array}{l}-0.00 \\
(0.01)\end{array}$ & $\begin{array}{l}-0.00 \\
(0.01)\end{array}$ & $\begin{array}{l}-0.00 \\
(0.01)\end{array}$ \\
\hline Sci. Faith Conflict & - & - & - & $\begin{array}{l}0.02 * * \\
(0.01)\end{array}$ & $\begin{array}{l}0.02 * * \\
(0.01)\end{array}$ & $\begin{array}{l}0.02 * * \\
(0.01)\end{array}$ & $\begin{array}{l}0.02 * * \\
(0.01)\end{array}$ \\
\hline Trust Drs. & - & - & - & $\begin{array}{c}-0.06^{* *} \\
(0.01)\end{array}$ & - & - & - \\
\hline Trust NGOs & - & - & - & $\begin{array}{c}-0.03 * * \\
(0.01)\end{array}$ & - & - & - \\
\hline Trust Govt. & - & - & - & $\begin{array}{c}-0.02 * * \\
(0.01)\end{array}$ & - & - & - \\
\hline Country Level Factors & & & & & & & \\
\hline Low Mid Inc & $\begin{array}{l}0.02 * \\
(0.01)\end{array}$ & $\begin{array}{l}-0.01 \\
(0.01)\end{array}$ & $\begin{array}{c}0.02 \\
(0.01)\end{array}$ & $\begin{array}{l}-0.02 * \\
(0.01)\end{array}$ & $\begin{array}{l}-0.02 \\
(0.01)\end{array}$ & $\begin{array}{c}-0.02 \\
(0.01)\end{array}$ & $\begin{array}{l}-0.02 \\
(0.01)\end{array}$ \\
\hline Upper Mid Inc & $\begin{array}{l}0.06^{* *} \\
(0.01)\end{array}$ & $\begin{array}{l}-0.00 \\
(0.02)\end{array}$ & $\begin{array}{c}0.06 * * \\
(0.01)\end{array}$ & $\begin{array}{l}-0.02 \\
(0.02)\end{array}$ & $\begin{array}{l}-0.01 \\
(0.02)\end{array}$ & $\begin{array}{c}-0.01 \\
(0.02)\end{array}$ & $\begin{array}{l}-0.01 \\
(0.02)\end{array}$ \\
\hline High Inc & $0.09 * *$ & -0.01 & $0.09 * *$ & -0.02 & -0.01 & -0.01 & -0.02 \\
\hline
\end{tabular}




\begin{tabular}{|c|c|c|c|c|c|c|c|c|}
\hline & & $(0.01)$ & $(0.03)$ & $(0.01)$ & $(0.03)$ & $(0.03)$ & $(0.03)$ & $(0.03)$ \\
\hline & Comm. Disease Per Capita & - & - & $0.07 * *$ & $0.07 * *$ & $0.07 * *$ & $0.07 * *$ & $0.07 * *$ \\
\hline & & & & $(0.03)$ & $(0.02)$ & $(0.02)$ & $(0.03)$ & $(0.03)$ \\
\hline & $\%$ Internet Access & - & $0.14 * *$ & - & $0.16 * *$ & $0.20 * *$ & $0.16 * *$ & $0.16 * *$ \\
\hline & & & $(0.05)$ & & $(0.04)$ & $(0.04)$ & $(0.04)$ & $(0.04)$ \\
\hline & Interactive Tests & & & & & & & \\
\hline & Trust Doctors & - & - & - & - & $\begin{array}{l}-0.02 \\
(0.02)\end{array}$ & - & - \\
\hline & Doc X Internet & - & - & - & - & $\begin{array}{c}-0.11 * * \\
(0.03)\end{array}$ & - & - \\
\hline & Trust NGOs & - & - & - & - & - & $\begin{array}{c}-0.03 * * \\
(0.01)\end{array}$ & - \\
\hline & NGO X Internet & - & - & - & - & - & $\begin{array}{c}-0.05 * * \\
(0.02)\end{array}$ & - \\
\hline & Trust Government & - & - & - & - & - & - & $\begin{array}{c}-0.03 * * \\
(0.01)\end{array}$ \\
\hline & Govt X Internet & - & - & - & - & - & - & -0.02 \\
\hline$\vec{\omega}$ & & & & & & & & $(0.02)$ \\
\hline & Fixed FX Constant & & & & & & & \\
\hline & $\beta_{0}$ & $0.09 * *$ & $0.07 * *$ & $0.09 * *$ & $0.11 * *$ & $0.08 * *$ & $0.08 * *$ & $0.08 * *$ \\
\hline & & $(0.01)$ & $(0.01)$ & $(0.01)$ & $(0.01)$ & $(0.01)$ & $(0.01)$ & $(0.01)$ \\
\hline & $\begin{array}{l}\text { Random FX Var. } \\
\text { Components }\end{array}$ & & & & & & & \\
\hline & $\ln \left(\sigma_{\text {Country }}\right)$ & $-2.79 * *$ & $-2.82 * *$ & $-2.79 * *$ & $-2.88 * *$ & $-2.87 * *$ & $-2.84 * *$ & $-2.83 * *$ \\
\hline & & $(0.07)$ & $(0.07)$ & $(0.07)$ & $(0.07)$ & $(0.07)$ & $(0.07)$ & $(0.07)$ \\
\hline & $\ln \left(\sigma_{\text {Residuals }}\right)$ & $-1.76 * *$ & $-1.76 * *$ & $-1.76 * *$ & $-1.77 * *$ & $-1.77 * *$ & $-1.75 * *$ & $-1.75 * *$ \\
\hline & & $(0.06)$ & $(0.06)$ & $(0.06)$ & $(0.05)$ & $(0.05)$ & $(0.05)$ & $(0.05)$ \\
\hline & $\mathrm{N}$ & 130734.0 & 127059.0 & 129819.0 & 117054.0 & 117054.0 & 117054.0 & 117054.0 \\
\hline & & 0 & 0 & 0 & 0 & 0 & 0 & 0 \\
\hline
\end{tabular}

Note. Mixed multilevel linear model coefficients presented with standard errors in parentheses. The outcome variable in all models is an interval level of vaccine skepticism, scored to range from 0-1. Models include variance components for country random effects, and include two different sets of fixed effects; factors that vary at the individual respondent level (e.g., trust in doctors, government), and factors that vary across countries (e.g., internet access, economic development). All models include individual-level probability weights when estimating the fixed effects portion of the model. 